\title{
C.A.S. ART EXHIBIT 1970
}

First C.A.S. Art Exhibit, held in Winnipeg during June meeting, 1970, comprised of 18 entries. The Exhibit was set up at the Fort Garry Hotel on June 21-25, adjacent to the meeting. The entries were judged by Miss B. Pitman, Art Educator with the Winnipeg Art Gallery, and the following were chosen:

\author{
OIL \\ 1st-"STILL LIFE" \\ Mrs. J. Whalen, Islington, Ontario \\ Hon. Mention-"HOUSE IN TENERIFE" \\ Dr. Ming Yao, Ottawa, Ontario \\ WATER COLOUR \\ 1st-Entry No. 3 \\ Yves Jacques, Sillery, Quebec \\ COLOUR PHOTOGAAPHY \\ 1st-"VILLAGE WELL" \\ Mrs. R. A. Gordon, Toronto, Ontario \\ Hon. Mention-Entry No. 17 \\ Dr. A. J. Dunn, Toronto, Ontario \\ SPECIAL, SCULPTURE, CERAMICS, THREE DIMENSIONAL DESIGN \\ 1st-"HEAD" Sculpture \\ Daphne Peterson, Vancouver, British Columbia \\ 1st-Teak Bowls-Wood Sculpture \\ Dr. B. Shell, Winnipeg, Manitoba \\ Hon. Mention No. 1-"FIGURE" Ceramics \\ A. Paterson, Vancouver, British Columbia \\ Hon. Mention No. 2-“CATERPILLAR" Paper \\ M. Wade, Winnipeg, Manitoba
}

\section{INFORMATION SERVICE}

At the recent annual meeting of the Canadian Anaesthetists' Society a motion was passed recommending the establishment of an Information Service to assist members and members-elect seeking appointment, and to assist Departments interested in receiving applications.

A committee will be appointed to commence this Service at the next session of Council.

In the interim, members of the Society may communicate with the Secretary at 178 St. George Street, Toronto 5, Ontario.

A. B. NoBle, M.D. Secretary 